\title{
Thermoelectric Module for Low-Voltage Loads
}

\author{
Reynaldo G. Salamat \\ Bulacan State University, Malolos, Philippines \\ Email: reysalamat3@yahoo.com
}

Received 25 October 2014; revised 28 November 2014; accepted 17 December 2014

Copyright (C) 2014 by author and OALib.

This work is licensed under the Creative Commons Attribution International License (CC BY). http://creativecommons.org/licenses/by/4.0/

\section{Abstract}

The focus of this paper is to develop a thermoelectric module for low-voltage loads that will satisfy the electrical use and stored charges in the improvised power bank that can be used by the students and the faculty in everyday life or even in emergency. This project will benefit the BIT and COE students of the Bulacan State University, and the professionals: drafters, architects, engineers or even hikers, adventure seekers and future researchers. The thermoelectric module is composed for low-voltage loads as computer processor coolers, DC motor, LED lamp and most specially the thermoelectric module applications. All the necessary equipment is researched and gathered together into the project making mini-generator used in a smart, nice and in most usable way by the students. It has a thermoelectric module that converts temperature into electricity. The body is made up of wood that holds and protects the project. The project is made up of locally available materials. The findings of the study revealed that the thermoelectric module for lowvoltage loads was functional, durable, user-friendly, cost-effective and safe. All materials are cheap, and have a good and trusted quality that may help the people in making life more convenient. The project was rated by (100) respondents from the drafting students and faculty. It gains an overall rating of (4.08) which means that the project is very acceptable. Specifically the researchers answered the objectives of the study that proved usefulness and safety of the project. Therefore, the evaluators are agreed to the acceptability of the project.

\section{Keywords}

Thermoelectric Module, DC Motor and LED Lamp

Subject Areas: Electric Engineering, Experimental Physics

\section{Introduction}

Philippine is a tropical country where we are only affected by two major seasons. The weather becomes hotter as the year goes by while one of the factors affecting our weather is the global tropical warming. Climate change 
affects the surface of the ozone layer which results to extreme heat and sometimes causes sudden change in our natural calamities.

Human societies have long been subject to disruption by climate change. In the past, it causes extreme weather events and periodic inundation to droughts and food scarcity. Climate change is likely to result from human actions and in particular from the burning of fossil fuels and changes in global patterns of land use. These and other developments lead to increasing the atmospheric concentrations of certain gases-chiefly carbon dioxide, methane and nitrous oxide - called greenhouse gases (GHGs) because of the accumulating in the upper atmosphere. They act like the roof of a greenhouse, trapping long-wave radiation and thus raising temperatures and provoking other forms of climatic disruption. This means that technology doesn't make our lives convenient sometimes and it causes destruction to our environment [1].

New technology impacts our daily lives in every field, from the cars we drive, cell phones we use, computers and networks we access and power we consume. In fact, humans have always been greatly affected with the developments in new technology. Some of the hot topics in new research technology include environment and renewable energy, space science, electronics, stem-cell investigations and many others.

In our country one of the problems we are facing is the hot weather. Because of global warming, summer is getting hotter every year. There are lots of things technology can offer us to solve this problem. Air conditioners or air coolers are good examples. They make air cooler by circulating them through Freon mechanism, similar to what happens to refrigerator. On the other hand, air conditioning contributes indirectly to the release of greenhouse gases and other pollutants that causes ozone depletion. So, it is better to use traditional electric fans than air conditioners though they work in different ways. Fans didn't make air cooler but they just make air feels cooler by moving it around. Thus, it is important that we consider the condition of our environment in choosing the technology we use. Also, air conditioners and refrigerators consume a lot of electricity. This creates financial disadvantages to the people who have to pay for the power consumption [2].

Every year there are approximately 19 typhoons entering the Philippine area of the responsibility. Some of these typhoons are devastating, killing many lives due to flashfloods and landslides and leaving major damages in some places. During calamities there will be also power outage. Rich people use mechanical generator to generate power during black-outs, but how about for those who can't afford to buy expensive generators? Most of typhoons victims are poor people because they live in remote places that are not properly developed. What if victims are stranded in their house during time of calamities and what they will do to have alternative source of power. An enough power to power up low current electrical devices will be essential during calamities.

Continuous electric rate hike is also a problem that we are facing nowadays. Almost all of the things in the market increase in price but the wages and salaries of workers remain the same. It's a burden for those who pay bills but for those who can't afford to pay for electricity connection it's hopeless. Considering the things that mentioned earlier the researchers decided to conduct the study that can be useful and also eco-friendly. This study aims to develop a low power generator that can be useful for all of the people. It can power up gadgets that are essential in everyday life, a generator that is powered by a candle. To maximize the power that has been produced by the generator, the researchers also decide to store the output power into an improvised power bank that will be useful during brownouts or in everyday life.

Lastly the finished project is hoped to be used as a model project for the students of Bulacan State University, and for the future researchers.

\subsection{Objectives of the Study}

The general objective of the study is to produce a thermo electric module for low voltage loads that is both useful and eco-friendly. It can be used by almost all of the people in emergency or unwanted circumstances like blackouts or even in everyday life.

Specifically it has the following objectives:

1) To produce a multi-purpose mini-generator;

2) To promote an alternative source of energy that can help in cutting down price in electric bills;

3) To produce an efficient mini-generator that will be essential during black-outs and power outrage;

4) To give some reliefs to remote communities in terms of power supply;

5) To evaluate the effectiveness of the improvised low-power generator in terms of:

a) User-friendly; 
b) Durability;

c) Functionality;

d) Cost effectiveness;

e) Aesthetics;

f) Safety.

\subsection{Conceptual Framework of the Study}

This part of the study focused on the different methods and processes employed in the construction of the project. The concept of the study was illustrated through a paradigm presented in Figure 1 with the input, process and output.

The input frame of the study consists of ideas taken from book [3], ideas from existing products and materials [4] tools and equipment used and ideas from adviser [5]. The process frame is about the different processes that have been used like actual design, assembling, testing, revising and evaluating of the said project. The output frame of the presented study is the finished proposed project which is to be known as the improvised lowvoltage power generator.

\section{Methodology}

\subsection{Project Description}

The purpose of the study is to provide a convenient thermoelectric module for low-voltage loads that can help not only students but also other people during black outs. This mini-generator can produce low current of electricity that may be stored in the improvised power bank to make other gadgets work.

The proposed project is composed of four 1" $\times 1$ " wood with a height of 14 inches for its base. It has a base of 7.5 " $\times 8.5$ " screwed tightly to serve as foundation of the product. There are two tubular steels to hold the lower heat sink which serves as the platform of the TEC module and the upper heat sink. At the right side face, the researchers made an improvised power outlet to directly charge the battery that will be placed in the improvised power bank [6]. The researchers are trying to maximize the generator use.

The bottom part of the frame is protected with glasses for prevention on upcoming wind. It also helps the candle to produce more consistent flame and to make it operate continuously. The upper part is a screen to let the air flow gently to feed the flame of the candle it also serves as protection for the inner parts of the project stand.

The generator's most important part is the thermoelectric cooler (TEC module) along with the heat sink and improvised power bank. The TEC serves as the heart of the given study. During exposing to heat, it produces electricity equivalent to the heat it absorbs. The higher the heat the higher electricity it will produce. The heat sink regulates the heat to prevent the TEC from overheating. The improvised power bank is a box-like storage for the batteries charged by the TEC. It increases the use of the generator and can operate other gadget simultaneously (Figure 2 and Figure 3).

\subsection{Project Structure}

Nails, screws and bolts are needed to fasten the project parts. The outer part of the project is made up of a high

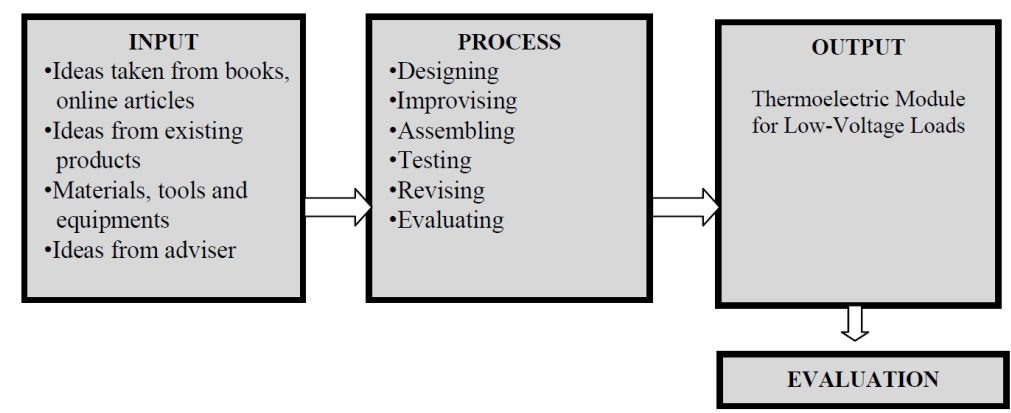

Figure 1. Conceptual framework of the study. 


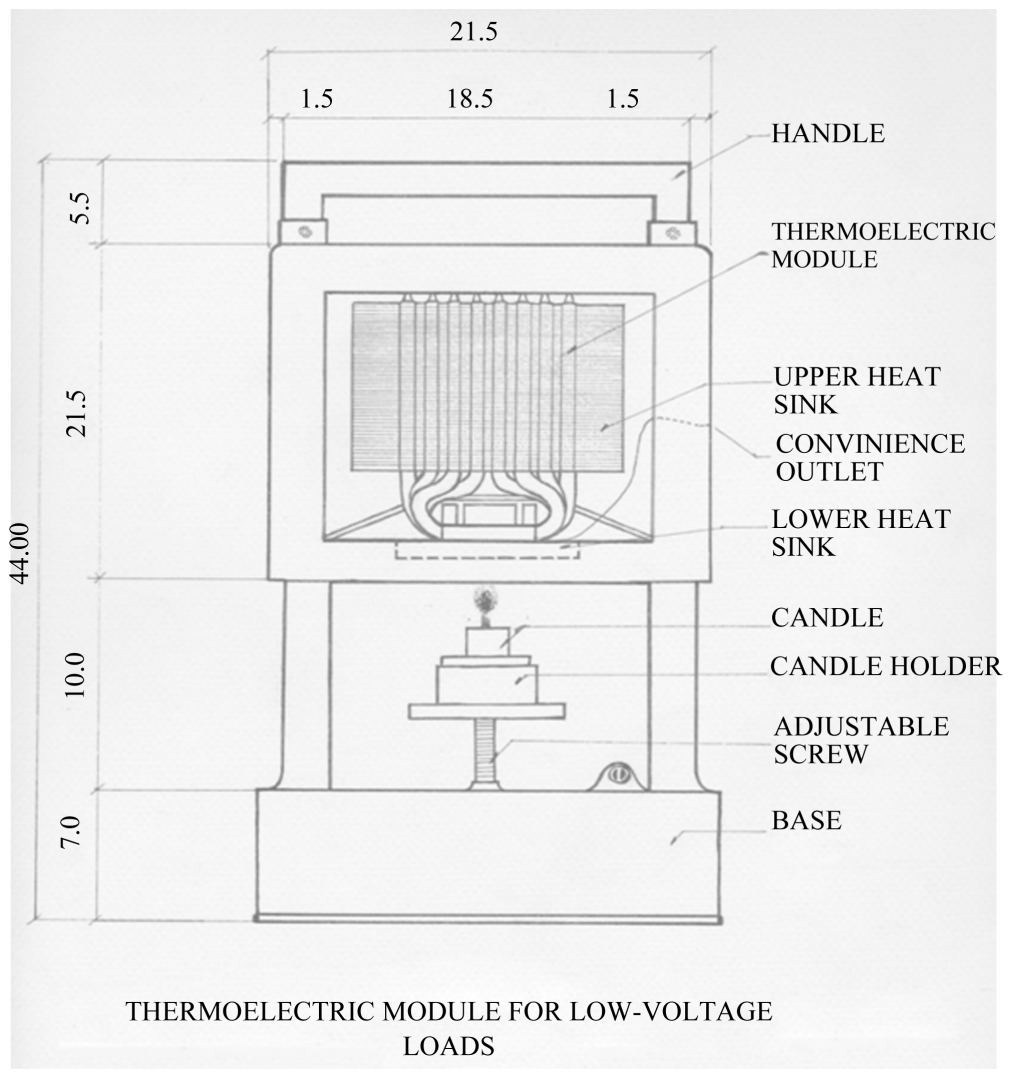

Figure 2. The parts and actual dimension of the thermoelectric module for low voltage.

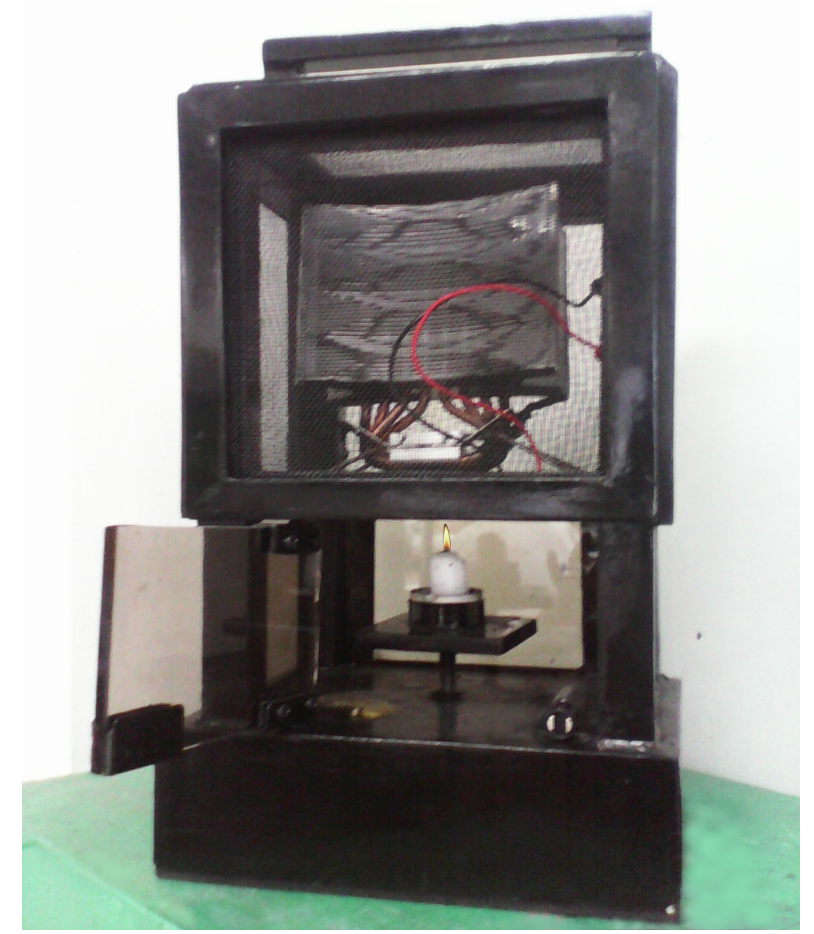

Figure 3. The actual finish project of the thermoelectric module for low voltage loads. 
quality wood. The three major parts of the project are:

1) Heat sink: It is a computer part that regulates the heat on the surface to prevent the TEC module from overheating.

2) TEC module: It is the main part of the project. It converts the heat energy into electricity.

3) Improvised power bank: It is a box-like case that stores the battery of the TEC module in a charged condition.

\subsection{Project Capabilities}

The project is designed to provide a safe and useful mini generator for everyone to sustain their needs in electricity whenever they need it. It is preferred to use when there is a black out. It has a power bank where you can use other gadgets simultaneously like mini fan and LED light. The power bank can serve directly as a charger for some gadgets like cell phone, speaker or MP3.

The project can be implemented for outdoor as well. It fits to people loved outdoor activities. The presented project itself is portable although its power bank is built separately to make it easier to carry.

\subsection{Project Limitations}

The researchers provided only a mini generator that can produce up to 2 - 3 volts which means only low powered gadgets can only be utilized.

\section{Result of Project Evaluation}

The project has been tested for its workability. Demonstration is performed to determine whether the lowvoltage generator could deliver the necessary function, it was required of. The evaluation process was done by conducting a survey on the acceptability of the generator and validity of the project application.

The respondents were (94) drafting students and (6) drafting professors. A structural questionnaire was considered for the evaluation. The evaluators rate the generator by the following criteria: 1) Multi-purpose; 2) Alternative source of energy; 3) In case of emergency; 4.1) User-friendly; 4.2) Durability; 4.3) Functionality; 4.4) Cost effectiveness; 4.5) Aesthetics; 4.6) Safety. The evaluation criterion has been listed for different numerical ratings in Table 1.

In items under of "set criteria" of the project, the evaluators agreed as revealed in Table 2, where the project was rated "very acceptable" in each criterion by the general method of computing of overall mean rating 4.08.

It can be seen that, this project can help the different kinds of people to keep using their gadgets even when they are outside a particular building. This may be reached by using the product you can charge a battery of a cellular phone, have a blast using an electric fan, and have a light in darkest hours. It should be mentioned that, the materials used in the whole project have the best quality, durability, ease of operation, cheap because all materials are available locally, and also safe for implementation. The indicators obtained an mean rating 4.23 in item User-friendly, in item Durability the average mean was 4.01, for the item Functionality the mean was 4.11, Cost effectiveness rated average mean 4.10, for the item Aesthetics the mean was 3.84, and in the item of Safety the indicators obtained an mean average 4.13 respectively. All these results certify that the group of evaluators agreed on the acceptability of the research project.

\section{Results}

The presented study has discussed the thermoelectric module for low-voltage loads. Generally, the performance of the project is very acceptable. It works well enough as a generator for low current electrical appliances that can be useful for everyone.

Specifically the following objectives are answered:

1) The project can produce a multi-purpose generator. It will be considered as a multi-purpose because there are so many gadgets using USB type wire for our improvised power bank that can plug-in the gadgets, like a fan, LED, or a mobile charger.

2) This can be an alternative source of power in case of black-outs. In that kind of scenario the only thing that you will need is a candle, candles are very common to everybody because it gives light in dark hours of emergency. 
Table 1. The evaluation criteria for thermoelectric module for low-voltage loads.

\begin{tabular}{cc}
\hline Numerical rating & Descriptive rating \\
\hline $4.51-5.00$ & Highly acceptable \\
$3.51-4.50$ & Very acceptable \\
$2.51-3.50$ & Acceptable \\
$1.51-2.50$ & Slightly acceptable \\
$1.00-1.50$ & Unacceptable \\
\hline
\end{tabular}

Table 2. Summary of mean score and descriptive rating.

\begin{tabular}{ccc}
\hline Criteria & Mean & Descriptive rating \\
\hline Users friendly & 4.23 & Very acceptable \\
Durability & 4.01 & Very acceptable \\
Functionality & 4.11 & Very acceptable \\
Cost effectiveness & 4.10 & Very acceptable \\
Aesthetics & 3.84 & Very acceptable \\
Safety & 4.13 & Very acceptable \\
Overall rating & $\mathbf{4 . 0 8}$ & Very acceptable \\
\hline
\end{tabular}

3) This project appears to be surely efficient because the improvised power bank anyone can now be utilized anywhere. Also, it is more efficient to apply the power bank since the stored energy there is stable. Unlikely, with the generator the output power depends on the candle.

4) The effectiveness of the low-voltage power generator would be indicated in terms of:

4.1) User-friendly: The user-friendly of this study is very acceptable as it is easy to operate. It can also operate individually because candle is the main source of power. It is very common for all so nobody will have a hard time in operating this generator.

4.2) Durability: In terms of durability of this study it is very acceptable because this was fixed by nails and made of good wood bars.

4.3) Functionality: The functionality is very acceptable since it can be performed simultaneously. Anyone can take this until what time required. It's also increased the use of power produced aside from the light that this will give us. Thus, it brings the heat needed for the TEC module in order to convert heat to an electric energy or in other word, the voltage.

4.4) Cost-effectiveness: The cost effectiveness of this project is very acceptable. Since the materials are made of cheap materials and some of these are available in the market. However, other materials like the TEC module are not that familiar to other stores but can be easily obtain through online shopping.

4.5) Aesthetics: The aesthetics of this project is very acceptable, although this was made up of wood materials. Its attractiveness doesn't affect the product because of the color and design use for the product.

4.6) Safety: The safety of this project is very acceptable because there are no sharp edges in contrast. There is a candle involve here that can be a source of burning; however the safeness will be on the users handling of this product.

\section{Conclusions}

Based on the findings generated from the given study, the following conclusions can be derived.

1) With this project, many people discover that candle and other source of heat are a good source of renewable energy. It is sometimes wasted and it can be useful to everybody for everyday life.

2) The study will serve as baseline information for those who want to conduct more extensive research about renewing heat energy into electricity and making a more efficient generator.

3) The low-voltage generator is simple and easy to use. All used materials are replaceable, easy to operate, and very useful for everyone. The proposed project is very acceptable in terms of accessibility or user friendliness.

4) The low-voltage generator may be operated manually without the need for any machines. It certifies very 
acceptable functionality.

5) The low-voltage generator can be used for long time because the main parts are locally detachable and cheap due to the cost effectiveness. It is also easy to repair or change damaged parts.

6) It is safely acceptable since there are no sharp edges on all sides and no dangerous materials.

\section{Recommendation}

According to the results and the findings of this work, it is recommended that:

1) Improvement of the design of the case makes it smaller as possible.

2) Aluminum bars instead of wood bars for the body to make it lighter in terms of weight to be easy portable.

3) Multi thermoelectric modules are required to produce more electricity.

4) The thermoelectric generator can be applied instead of thermoelectric module to produce higher amount of electricity.

5) Step-up converter may be introduced to multiply the output power.

6) The implementation of rechargeable power banks can directly charge the generator.

7) Installation of digital voltmeter is necessary to monitor the output voltage of the generator.

8) The use of Beeswax/Soy wax candle with the generator may be needed because those kinds of candles are eco-friendly.

\section{References}

[1] Managbanag, S.G. (1998) Alternative Source of Energy: The Quest for More Energy to Boost Economic Recovery. National Library of the Philippines.

[2] De Guzman, R. (2005) Scenarios and Strategies for Clean Power Development in the Philippines. National Library of the Philippines.

[3] Karri, M. (2011) Thermoelectric Power Generation System Optimization Studies. Clarkson University, New York. http://people.clarkson.edu/ bhelenbr/Research_Pages/Students_files/Madhav_PhD_Dissertation.pdf http://www.merriam-webster.com/

[4] Joohansson (2013) Thermoelectric Fan Powered by a Candle. http://www.instructables.com/id/Thermoelectric-Fan-Driven-by-a-Candle/

[5] Barron, K. (2005) Experimental Studies of the Thermoelectric Properties of Microstructured and Nanostructured Lead Salts. Massachusetts Institute of Technology. http://dspace.mit.edu/bitstream/handle/1721.1/32836/60689207.pdf?sequence=1

[6] Joohansson (2013) Smartphone Charger Powered by Fire. http://www.instructables.com/id/Battery-Charger-Powered-by-Fire/ 